\title{
US Businesses' Code Of Ethics As An Instrument To Comply With The Foreign Corrupt Practices Act
}

Paulina Diosdado De La Pena, West Virginia University, USA Presha Neidermeyer, West Virginia University, USA

\begin{abstract}
The Foreign Corruption Practices Act (FCPA) makes illegal bribing foreign officials by any US issuer, domestic concern, any type of organization with major place of business in the US and any US citizens. This paper will focus on the extent to which the FCPA is included in the Code of Ethics of Fortune 500 companies as a method of showing the importance of compliance with the Act. The following sections analyze the scope and limitations of this Act, the official compliance mechanisms and internal policies and training developed by five Fortune 500 companies in order to abide by the FCPA.
\end{abstract}

Keywords: Bribery, Code of Ethics, Foreign Corrupt Practices Act, Fraud

\section{INTRODUCTION}

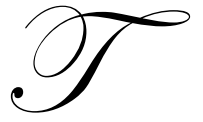

he foreign corrupt practices act is an important piece of legislation that was signed into law during the first year of the Carter Administration in 1977. During this time period there had been significant frauds taking place including the Lockheed, Northrop and Oil Gulf (Time, 1981). It was these acts of unethical business dealings that led governmental officials to enact the FCPA. The act was designed to stop the detrimental business outcomes of bribery including: the detrimental impact on America values, the diminishment of confidence in the free market system, and the US foreign policy issues created.

This paper will focus on the extent to which the FCPA is included in the Code of Ethics of Fortune 500 companies as a method of showing the importance of compliance with the Act. With the explicit inclusion of discussion of the Act in the Code of Ethics, companies instill in their employees and others a sense that compliance with the Act will be integrated into the culture of the company and will permeate into the daily business activities of the corporation. This suggests that not only will company comply with the day to day compliance requirements, but will take this one step further and compliance with the FCPA could be more easily achieved, if employees accept the plan and do not engage in future illegal behaviors. As a consequence, the company would be protected against successful legal action against to it, reducing blackmail, increasing the worldwide acceptance of the capitalist system and mounting economic interest (Pines, 1994).

\section{SCOPE AND IMPLICATIONS OF THE FCPA}

The FCPA prohibits the bribery of foreign officials by US issuers (publicly trade companies), domestic concerns (private companies), any kind of organization which is major place of business is in the US, and US citizens, and emphasizes that these parties may be liable for third party related transactions. It establishes the requirement of proper record and bookkeeping of the companies' assets, as a control mechanism (U.S. Department of Justice. House of Representatives, 1977).

Within the legislation, a bribe is defined like "anything of value" given to any foreign official. This definition increases the scope of a bribe to include not only monetary assets but also goods and services. The bribe 
does not actually have to be given in order to the party be subject to a legal action; rather a mere promise to deliver something of value for consideration in granting or retaining business makes it a violation of the FCPA (U.S. Department of Justice. House of Representatives, 1977). The FCPA does not apply to facilitating or grease payments, and also there are some cases in which the bribery is "acceptable" under the FCPA if the bribery is legal in the foreign country (U.S. Department of Justice. House of Representatives, 1977).

The two bodies in charge of enforcing the FCPA are the U.S. Department of Justice (DOJ) and the Securities and Exchange Commission (SEC). While some had previously argued that these two governmental agencies would not able to work together efficiently (Pines 1994), the latest trends suggest that this is not an issue. In fact, at a discussion panel in 2007 Department of Justice, Deputy Chief (Fraud Section-Criminal Division), Mark F. Mendelsohn at the International Corporate Compliance Conference (Maloney, 2007), highlighted:

1. "The number of investigations opened indicates a general increase in enforcement actions initiated under the FCPA by both the DOJ and the SEC.

2. A large volume of cases under investigation are a result of internal investigations referred to the DOJ.

3. The trend of voluntary corporate disclosures of bribery to the DOJ continues to increase as a result of Sarbanes-Oxley compliance, the increased likelihood of protection from the media through selfdisclosure, and increased whistleblower activity (...)"

\section{OFFICIAL COMPLIANCE MECHANISMS}

Unfortunately the FCPA only established that proper internal controls, records and bookkeeping must be established within the firm to avoid the wrongful use of the company's assets. Thus rather than set up a system of very specific rules and regulations, the Act merely requires a system for each corporation be in place. The issue rises in determining what is "proper" since there is no a quantitative benchmark to asses the degree until this requirement is fulfilled.

All the US issuers must submit their financial statements to the SEC, however, compliance with this requirement does not fulfill the FCPA requirements. The companies must develop an internal control system with significant due diligence, that in terms of record and bookkeeping is closely to an internal audit system with its corresponding auditing committee, closely working with a legal team.

Some other mechanism can be used, after consulting with the company's legal department if any ambiguity or uncertainty remains, the company may seek advice from the DOJ following the recommendation of Mark Mendelsohn expressed in the FCPA session at the $6^{\text {th }}$ Annual Compliance and Ethics Institute:

(...) DOJ is not in the business of providing guidance (...). A company may contact the DOJ, detailing a transaction in which it wishes to engage, but has not yet pursued, and inquire whether the DOJ would enforce an action based on the representations in the proposal (Jedlicka, 2007)

\section{FCPA POLICIES AND TRAINING IN FORTUNE 500 COMPANIES}

A very common statement of company's top personnel is "Our employees are our most valuable asset", this is based on the significant investment of resources on recruiting, training and building internal and external relationships with them and the value added that employees generate for the company. However, the human behavior is also an element that introduces a lot of uncertainty into a company's process and procedures, and this behavior can be a serious liability for the company when unethical issues are encountered. A way to limit those liabilities without constraining human creativity and development is implementing a company's culture and code of ethics that is entirely permeated into the daily business activities like Fredric F. Firestone from the SEC suggested in a discussion panel at the 2007 International Corporate Compliance Conference (Maloney, 2007).

In the following paragraphs the internal FCPA policy and its inclusion on the company's code of ethics is analyzed five companies in different industry sectors: 3M, Abbott Laboratories, Altria Group, AT\&T and Chevron. 


\section{$3 \mathbf{M}$}

The code of ethics displayed in 3M's website neither makes explicit reference to the FCPA, nor to the behavior that should be followed when an employee is encountered with a possible bribery situation. When conducting further research in $3 \mathrm{M}$ position in this matter a document was found on its website ${ }^{1}$, that addressees FACP within the scope of $3 \mathrm{M}$ related parties but not for $3 \mathrm{M}$ workers. This document's focus is Non-3M workforce such as consultants, sales agents and business partners.

The relevant points of the "Non-3M Workforce Anti-Bribery Policy" include:

1. a FCPA binding instrument in the form of a commitment letter for Non-3M workers, which must be signed and dated by the non-3M worker,

2. the establishment that facilitating payments can be a violation of anti-bribery laws,

3. the clear distinction between treatment to non-government officials (Business Gifts and Entertainment Policy for non-government officials) and government officials (Non-3M Workforce Anti-Bribery Policy),

4. the clear definition of "bribe", "improper advantage" and "government official", and also 3M policy to "accurately reflect all transactions on 3M's books are records"

5. a FCPA policy statement where 3M establishes to comply with the FCPA, all applicable anti-bribery laws and all local laws were it has operations,

6. the establishment of six requirements related to do not directly or indirectly engage in bribing, preventive actions, mandatory due diligence and reporting "any suspected violations by $3 \mathrm{M}$ employees, non-3M workers or others doing business before a Government Official on 3M's behalf," $(3 M, 2008)$

7. an internal policy of reviewing the policy with the worker "within the first week of assignment and on an annual basis" $(3 M, 2009)$. In this way they ensure that the FCPA policy is keep in mind in daily operations.

While the existence of any documentation is beneficial, the lack of applicability of this document or any explicit reference to the FCPA for 3M employees is somewhat troubling. Although it may be implied that such policy is also applicable to 3M employees, no room should be left for interpretation if the company's position can be jeopardized, and it should be explicitly established. The "commitment letter" is an important feature of $3 \mathrm{M}$ policy to Non-3M workers, and a positive aspect of it is that regardless of establishing a list of Dos and Don'ts, it keeps a principle base approach that encourages self-enforcement, self-regulation and good judgment.

\section{Abbott Laboratories}

Abbott Laboratories provides access to its 30 page "Code of Business Conduct" via its website (http://www.abbott.com/static/content/document/COBC_English.pdf). In this document all regulations related to Abbott business' practices are addressed such as: Food and Drug Laws, Federal Anti-Kickback Statute, Anti-money laundering Laws and the Foreign Corrupt Practices Act, among others.

In the FCPA section called "Laws Relating to Payments to Government Officials/Employees", the main focus is illustrating the general prohibitions of the statute and stating the company's principle-based position with regard to compliance with the legislation as compared to a rule based compliance system. The document provides a specific example of what behavior or business practice could be considered an "impermissible indirect activity" (Abbott Laboratories, 2004).

Within the document, Abbott Labs uses the noun, "We". A short explanation within the document as to who is subject to these regulations would be advisable given that it may be perceived to be applicable only to the direct employees of Abbott Laboratories and not to subcontractors, or agents, which was likely not the intention of the document.

A drawback of the "Code of Business Conduct" is its location under the "Investor Relations" tab, which may decrease the effectiveness of the tool in reaching its target internal audience. But a very positive feature is that

\footnotetext{
${ }^{1}$ Authorship confirmed by Christa McCloud from 3M Talent Acquisition Department
} 
the code is available in 33 languages, reflecting the awareness of Abbott Laboratories of its workforce diversity, and commitment to make understandable to everyone in the company in his/her first and second languages.

An outstanding feature about Abbott Laboratories is its "Ethics and Compliance Helpline". This is not only a tool to support day to day behavior and activities of its individuals, if the line is effectively perceived as anonymous and in practice is, but also it is a way to signal the company's policy to external parties.

\section{Altria Group, Inc.}

Altria Group, (formerly Phillip Morris) competes in the tobacco industry. Their revenues in 2007 were nearly $\$ 74$ billion US Dollars (Altria Group, 2008). It has in place an intensive "Compliance and Integrity Program" for all its companies. The Chief Compliance and Administrative Officer is Martin Barrington, who is also the Executive Vice-President of Altria (Altria Group, 2009). As an additional function for compliance, they have appointed compliance officers for each of its companies ${ }^{2}$ (Altria Group, April 2008). The installation of Martin Barrington as compliance officer combined with his other duties as a high ranking representative of the company, can be translated as the company sending a public message about their perceived importance of ethics within the corporation at all levels and in each activity.

Within the framework of this program, emerges the "Altria Code of Conduct for Compliance and Integrity" (Altria's Code), a 48-page document that is a rule-base code, which provides a system to evaluate daily activities keeping in mind a mental checklist before acting in order to ensure compliance with laws, regulations, statues and the company's policies and values, while highlighting personal responsibility and encouraging to seek advice when a non-standard situation is encountered. Altria has an "Integrity helpline" to encourage employees and related parties seeking advice and reporting activities of concern for the company.

Regarding the FCPA, the code establishes clearly the don'ts of the Act, while also explicitly covering Altria's position about facilitating payments by stating "Altria discourages these (facilitating payments)" (Altria Group, April 2008). The document does however provide a list of conditions that when met, allow such payments to be made. Altria's Code section regarding the FCPA seems to reduce the uncertainty for employee and related parties operations; however the overall lengthiness of the document may be detrimental in its practical execution. This is generally the trade-off that occurs between a rules-based (generally longer) and a principles-based (Generally shorter) documentation system.

The last paragraph of the FCPA section estates: "If you are involved in international business, contact Law support to make sure you understand the standards that apply to your business activities, including the laws on international bribery". This statement is closely to the Administrative Theory of self-regulation and selfenforcement, however, in a clearly rules-based code, encountering with this open gap may create confusion to the employee in regarding what is expected from him/her, as to whether he/she followed the rules or should substitute his/her own judgment.

Directors are subject to the "Altria Code of Conduct" and to the "Board of Directors Code of Ethics" (BOD Code). This may be perceived as Altria's expectations of its Board of Directors to meet a higher standard that the rest of the company's members, but to nonetheless comply with the same basic regulations. In the BOD Code, a pre-emptive position to FCPA violations is established: "as to whether a possible arrangement, payment or gift may violate these laws contact the Chair of the Nominating, Corporate Governance and Social Responsibility Committee before taking any action" (Altria Group, 2009) Interestingly, this position focuses on minimizing risk exposure by relying on the directors good judgment, which is rather peculiar given the reliance at lower levels of management on a rules-based system. .

\footnotetext{
${ }^{2}$ Phillip Morris USA, US Smokeless Tobacco Company, John Middleton, Ste. Michelle Wines Estate, Phillip Morris Capital Corporation and $28.5 \%$ ownership of SABMiller (http://www.altria.com/about_altria/1_2_companiesandbrands.asp)
} 


\section{AT\&T}

AT\&T does not explicitly include the FCPA in its Code of Ethics, instead it relies on an individuals' knowledge of related rules, regulations and applicable laws:

It is the Company's policy to comply with all applicable laws, rules and regulations. It is the personal responsibility of each employee, officer and director to adhere to the standards and restrictions imposed by those laws, rules and regulations in the performance of their duties for the Company, including those relating to accounting and auditing matters and insider trading (AT\&T, 2009).

This position is to general and it really does not offer guidance to employees, since it places all the responsibility directly on their shoulders. The company may want to reconsider its stance on guidance since it is unlikely that all members of its workforce and consultants are familiar with all potential laws under which they are operating, particularly in an international environment.

\section{Chevron}

Chevron started to continuously improve and update its Code of Ethics and recently included "The Chevron Way" as the firm's identity and policy, where an "Ethics Decision-Making" strategy is established in order for the employees integrate it in daily operations. The document is 28 pages, and the reference to the FCPA is brief. The internal policy is represented on 3 basic ideas:

1. "Bribery Is Always Prohibited"

2. "Employees with duties involving trade or travel outside of the U.S. must be familiar with this act"

3. "Management approval is required before any gift or payment can be made to a government or public official. In some cases, the gift or payment must also be approved by your Reporting Unit's Compliance Coordinator or Corporate Compliance" (Chevron, 2008).

The statement "Bribery Is Always Prohibited" basically summarizes Chevron position. The company also encourages self-education and self-regulation of its employees. However the third statement may confuse employees because it establishes that some gifts and payments can be made to a foreign government official. Mainly, Chevron needs to clarify when a payment or a gift is allowed and when it would be considered a bribe.

\section{SMALL AND MEDIUM SIZE COMPANIES}

Small and medium size (S\&M) companies must comply with the FCPA and put in place similar mechanism of internal audit, records and proper bookkeeping. Also, they should create a company's culture, code of ethics and clear position of what is expected from its employees.

For S\&M companies, pre-emptive actions towards the FCPA compliance are even more critical due to their relatively smaller size and thus potential vulnerability to large fines imposed by the US authorities. An awareness of this fact has to be raised at all levels of the firm, since knowing the scope of the consequences will encourage employees to do what is best to the firm in the long-term, and not seek only short-run gains.

The Small Business Administration helps small business to export and to get familiar with the laws that apply to them when they are ready to export. Closely working in this area, the Export-Import Bank is a good source of information regarding "Transaction due diligence best practices" (Export-Import Bank, 2008)

\section{CONCLUSIONS}

The FCPA prohibits bribing foreign government officers, and places a great responsibility on the companies in terms of employees and related third parties that can act on their behalf. It also demands for the implementation of an internal control system and proper record and bookkeeping, however the extend of what can be considered as "proper" is not specified. 
When a company is dealing with individuals located overseas, culture plays a key role on the individual behaviors, values and interaction. In order to control the uncertainty that can be introduced by these differences, even in the domestic arena, companies should take affirmative steps to build its policy and corporate culture that establishes a single set of rules, values or principles applicable regardless of the individuals' location.

A repetitive lack of the Administrative Theory application was found in the five companies analyzed when they addressed the FCPA policy. The importance of such theory resides in its focus of explaining to the individual why should he/she should comply with a rule, and also making the individual aware of the consequences magnitude related to his/her actions if he complies or not. As a result, it raises self-control, self regulation and self-enforcement, in this way, not all the enforcement is delegated to the overseeing body.

The desirable features related in general to the company's code of ethics and particularly, to its FCPA policy can be summarized by:

1. Making sure that top management is actively involve on the ethics procurement

2. Ensuring availability of the document, and in the right location, and in several languages to assure that everyone is able to read and understand it,

3. Providing a helpline and establishing the protection of whistleblowers,

4. Having in place a written and signed commitment,

5. A good balance between the general idea that is communicated and the specific details, in order to provide enough knowledge about the policy but not extremely lengthy that at the end nothing is retained,

6. Clearly specifying who is subject to the code of ethics, not assuming the individual will infer that he/she should comply with it,

7. Specifying what laws are related to the business, and

8. Continuous training and reviewing policies, on an annual basis at a minimum.

\section{LIMITATIONS AND FUTURE RESEARCH}

Rather than being limited to large companies, the Foreign Corrupt Practices Act also applies to all companies who export goods. The US Census in 2009 suggests that ninety-seven percent of all exporters are small and medium sized companies and that these companies account for thirty percent of all exports value. Future research could be conducted to ascertain whether these firms are also included the FCPA within the construct of their individual Codes of Ethics, since it has been shown that it effectively changes the employees' awareness in this matter, and potentially decreases the liabilities that may rise from a violation of the FCPA.

\section{AUTHOR INFORMATION}

Paulina Diosdado holds a BSCE from University of Guanajuato and a MSCE from West Virginia University (WVU). Currently, she is a MBA candidate at WVU, and works as GRA for the Department of Civil Engineering. She is a member of the Honor Society of Phi Kappa Phi and Society of Women Engineers, and is an Engineer in Training by WV State Board of Registration for Professional Engineers

E-mail: mdiosdad@mix.wvu.edu

Presha E. Neidermeyer, Ph.D. CPA is a faculty member in the Division of Accounting within West Virginia University's College of Business and Economics. Her research specialty includes the impact of culture on behavior and gender issues, which are published in numerous journals. She is the co-author of Use What You Have: Resolving the HIV/AIDS Pandemic. Her teaching specialties include financial and international accounting. She is an active participant in various organizations benefiting charities in Africa. She has led multiple teams to Africa of business people interested in using their special skills to help minimize the impact of the AIDS Pandemic. 


\section{REFERENCES}

1. 3M (2008, October 31). Non-3M Workforce Anti-Bribery Policy. Retrieved March 1. 2009, from Global Enterprise Digital Media Repository. Website: http://multimedia.mmm.com/mws/mediawebserver.dyn?6666660Zjcf6lVs6EVs66s7tPCOrrrrQ-

2. 3M (2009). Non-3M Workforce System. 3M Supplier Training Presentation. Retrieved April 11. 2009, from Global Enterprise Digital Media Repository. Website http://multimedia.mmm.com/mws/mediawebserver.dyn?6666660Zjcf6lVs6EVs66sW\&DCOrrrrQ-

3. Abbott Laboratories (2004). Code of Business Conduct. Retrieved March 17, 2009, from Investor Relationships-Corporate Governance. Website: http://www.abbott.com/static/content/document/COBC_English.pdf

4. Altria Group (2008). Financial Highlights-Consolidated Results. Retrieved Aprill 11, 2009, from Altria Group, Inc. 2007 Annual Report. Website: http://www.altria.com/annualreport/ar2007/2007ar_02 0100.aspx

5. Altria Group (April, 2008). Altria Code of Conduct for Compliance and Integrity.. Retrieved April 6, 2009, from Altria Managing Responsibility-Compliance and Integrity. Website: http://www.altria.com/download/pdf/responsibility_Altria_Code_of_Conduct.pdf

6. Altria Group (2009). Code of Business Conduct and Ethics for Directors. Retrieved Aprill 6, 2009, from Corporate Governance-Board of Directors. Website: http://www.altria.com/download/pdf/responsibility_Altria_Code_of_Conduct.pdf

7. Altria Group (2009). Martin J. Barrington.. Retrieved April 11, 2009, from About Altria - Our Management Team. Website: http://www.altria.com/about_altria/biography/1_4_2_barrington.asp

8. American Financial Group (2004) Code of Ethics. Retrieved April 6, 2009 from Corporate Governance. Website: http://www.afginc.com/phoenix.zhtml?c=89330\&p=irol-govconduct\#20

9. AT\&T (2009). AT\&T Inc. Code of Ethics. Retrieved March 25, 2009, from Investor Relations. Website: http://www.att.com/gen/investor-relations?pid=5595

10. Chevron (2008). Business Conduct and Ethics Code. Retrieved April 6, 2009 from Corporate Governance. Website: http://www.chevron.com/documents/pdf/chevronbusinessconductethicscode.pdf

11. Export-Import Bank of the U.S. (2008). Transaction due diligence best practices. Retrieved March 10, 2009, from Publications. Website: http://www.exim.gov/pub/pdf/Due-Diligence-Guidelines.pdf

12. Jedlicka, A. (2007, November). FCPA Enforcement Risks and Mitigation Strategies. (Cover story). Federal Ethics Report, 14(11), 1-4. Retrieved February 14, 2009, from Academic Search Complete database

13. Maloney, P. (2007, April). Anti-Corruption Compliance for U.S. Businesses. Federal Ethics Report, 14(4), 8-11. Retrieved February 14, 2009, from Academic Search Complete database.

14. Pines, D. (1994, January). Amending the Foreign Corrupt Practices Act Include a Private Right of Action. California Law Review, 82(1), 185. Retrieved February 14, 2009, from Academic Search Complete database

15. The Carter Center (2009). Jimmy Carter- Biography of the $39^{\text {th }}$ President of the United States. Retrieved April 9, 2009, from News and Publications. Website: http://www.cartercenter.org/news/experts/jimmy carter.html

16. Time (1981). Big Profits in Big Bribery. Retrieved April 17, 2009, from U.S. Website: http://www.time.com/time/magazine/article/0,9171,922462,00.html

17. U.S. Department of Justice. House of Representatives (1977) Unlawful Corporate Payments Act of 1977. Retrieved March 10, 2009, from Report No.95-640. Website:

http://www.usdoj.gov/criminal/fraud/fcpa/history/1977/houseprt.html

18. U.S. Census Bureau (2009). A profile of U.S. Exporting Companies, 2006-2007. Retrieved April 10, 2009, from U.S. Census Bureau News. Website: http://www.census.gov/foreign-trade/Press-

Release/edb/2007/text.pdf 


\section{NOTES}

